\title{
HIGH EFFICIENCY OF THE GRAIN MARKET IN THE POST-CRISIS DEVELOPMENT OF AGRIBUSINESS
}

\author{
РОСТ ЭФФЕКТИВНОСТИ ФУНКЦИОНИРОВАНИЯ РЫНКА ЗЕРНА \\ В ПОСТКРИЗИСНЫЙ ПЕРИОД РАЗВИТИЯ АПК
}

\author{
A. Tsvyrko, Candidate of Economic Sciences
}

А.А. Цвырко, кандидат экономических наук

Orel State Agrarian University, Orel City, Russia

Орловский государственный аграрный университет, г. Орёл, Россия

Phone: +7 (4862) 76-11-28, E-mail: ser2508@ rambler.ru

Received October 18, 2012

\begin{abstract}
In article priorities of effective functioning of grain market in the conditions of post-crisis development of agro-industrial complex economy of Russia are considered. Dynamic changes of outputs of agricultural production in the Orel region are presented, influence of production factors on results of economic activity is investigated. The role of state regulation, financial support and agricultural insurance in further forward development of the highly effective market of grain of the region is proved.

\section{АННОТАЦИЯ}

В статье рассматриваются приоритеть эффективного функиионирования рынка зерна в условиях посткризисного развития экономики агропромышленного комплекса России. Представлены динамические изменения объемов производства сельскохозяйственной продукиии в Орловской области, исследовано влияние производственных факторов на результаты хозяйственной деятельности. Обоснована роль государственного регулирования, финансовой поддержки и сельскохозяйственного страхования в дальнейшем поступательном развитии высокоэффективного рынка зерна региона.
\end{abstract}

\section{KEY WORDS}

Agrarian sector of economy; Grain Market; Orel region; Factor; Production; Agricultural insurance; Efficiency; Financial support; State regulation.

\section{КЛЮЧЕВЫЕ СЛОВА}

Аграрный сектор экономики; Рынок зерна; Орловская область; Фактор; Производство; Сельскохозяйственное страхование; Эффективность; Финансовая поддержка; Государственное регулирование.

Целью сельскохозяйственного производства всегда являлось и остается наиболее полное удовлетворение потребностей общества в высококачественной продукции. Один из ведущих ученых страны членкорреспондент Российской академии наук А. А. Жученко, занимающийся исследованием проблем фундаментальных и прикладных научных приоритетов адаптивной интенсификации растениеводства в XXI в., отмечал, что на протяжении всей истории ни одной нации не удавалось повысить свое благосостояние и добиться развития эконо- мики без предварительного наращивания производства продуктов питания [3]. В связи с этим оценка эффективности развития сельского хозяйства и представляющих его организаций, как и всех других отраслей народного хозяйства, включает, прежде всего, мониторинг показателей размера производимой продукции. Объем производства в расчете на душу населения зависит от уровня развития производительных сил и характера определяющих производственных отношений, а также от отраслевой и социальной структуры производства, от природных 
условий и ряда других факторов. Комплексное исследование проблемы продовольственного обеспечения регионов Российской Федерации показало, что угроза продовольственной безопасности исходит от сферы производства [1].

Анализ динамических изменений объемов производства сельскохозяйственной продукции в целом и в расчете на душу населения по Орловской области показал рост по зерну, овощам и мясу. Так, в 2010 г. уровень производства зерна надушу населения, превысил значение 1990г. на 27,3 \%, значение 2000 г. - на 84,6\%.

Многочисленные исследования ученых-аграрников свидетельствуют, что развитие агропромышленного комплекса Российской Федерации во многом определяется эффективным функционированием рынка зерна. Значимость этого сектора определяется как стратегическим характером продукта, так и масштабами зернового производства, его обширными межотраслевыми связями, которые оказывают влияние на состояние всей экономики. Следовательно, основой разрешения проблемы продовольственной безопасности должно стать эффективное развитие зерновой отрасли в стране и ее регионах.

Эффективность рынка зерна во многом определяется территориально-отраслевым разделением труда, т. е. особенностями почвенных, климатических и экономических условий функционирования. Рассмотрим территориальный аспект производства зерна в Орловской области. Самым крупным производителем региона за анализируемый период является Ливенский район, от которого своеобразный зерновой пояс протянулся на запад и северо-запад, включая в себя Мценский, Орловский, Должанский, Покровский, Свердловский, Колпнянский, Верховский, Новодеревеньковский и Залегощенский районы [5]. Эти районы также имеют высокие показатели урожайности зерновых культур. Самые низкие уровни производства и урожайности зерна характерны в основном для западных и юго-западных районов Орловской области, что во многом объясняется качеством почв. По этой же причине более высокие показатели производства и урожайности имеют практически все юго-восточные районы.
Анализ показателей размера производимой продукции в динамике свидетельствует, что административные районы Орловской области не утратили своих позиций в обеспечении населения зерном. Более того, объемы производства в ведущих зернопроизводящих районах региона увеличились.

Однако показатели объемов производства, несмотря на их исключительную важность с точки зрения удовлетворения потребностей общества в определенных видах продукции, не раскрывают экономической стороны производства, не дают ответа на вопрос о том, во что обходится, какой ценой достигнут указанный рост продукции. Между тем производство сельскохозяйственной продукции может происходить при разной величине затрат, при разном объеме и разной степени использования ресурсов, т.е. при разной экономической эффективности производства [4]. При этом сокращение затрат на единицу продукции создает возможность увеличить объем продукции в данной отрасли или в других отраслях народного хозяйства.

Исследования ученых-аграрников второй половины XX - начала XXI вв. подтверждали выдвигаемые постулаты, что одним из важнейших резервов повышения эффективности возделывания зерновых культур является концентрация производства, под которой понимают сосредоточение средств и рабочей силы, ведущее к увеличению производства. Считалось, что концентрация производства является объективным требованием повышения эффективности производства и позволяет снизить издержки в расчете на единицу продукции и увеличить прибыль на 1 га.

Данные группировки сельскохозяйственных организаций по размеру посевных площадей зерновых культур, представленные в табл. 1, показывают, что в общей численности предприятий, занимающихся возделыванием зерновых, 50\% имеют площадь до 2000 га, $40 \%$ - от 2000 до 6000 га, 10\% свыше 6000 га. Средний размер посевной площади зерновых культур по рассматриваемой совокупности равен 2700 га и изменяется от 470 га (ООО «Благодать» Новодеревеньковскогорайона) до 10485 га (ЗАО «Агрофирма Сельхозинвест» Ливенского района). 
Таблица 1 - Экономическая эффективность производства зерна в зависимости от размера посевной площади зерновых культур в сельскохозяйственных организациях Орловской области, 2010 г.

\begin{tabular}{|c|c|c|c|c|c|c|}
\hline \multirow{2}{*}{ Показатель } & \multicolumn{5}{|c|}{$\begin{array}{l}\text { Группы хозяйств по размеру площади посе- } \\
\text { вов зерновых культур, га }\end{array}$} & \multirow{2}{*}{$\begin{array}{l}\text { В среднем по } \\
\text { совокупности }\end{array}$} \\
\hline & $\begin{array}{c}\text { до } \\
1000\end{array}$ & $\begin{array}{l}1000 \\
1-2000\end{array}$ & $\begin{array}{c}2000 \\
1-3000\end{array}$ & $\begin{array}{l}3000 \\
1-6000\end{array}$ & $\begin{array}{c}\text { свыше } \\
6000\end{array}$ & \\
\hline $\begin{array}{l}\text { Количество сельскохозяйственных орга- } \\
\text { низаций }\end{array}$ & 7 & 18 & 15 & 5 & 5 & 50 \\
\hline Площадь зерновых культур, га & 720 & 1533 & 2523 & 4550 & 8352 & 2700 \\
\hline Урожайность, ц/га & 27,3 & 29,8 & 32,3 & 34,9 & 39,7 & 34,3 \\
\hline $\begin{array}{l}\text { Производственная себестоимость } 1 \text { ц } \\
\text { зерна, руб. }\end{array}$ & 197,7 & 267,5 & 252,1 & 297 & 267,8 & 266,5 \\
\hline $\begin{array}{l}\text { Себестоимость } 1 \text { ц реализованного зерна, } \\
\text { руб. }\end{array}$ & 216,3 & 262,2 & 246 & 281,9 & 269,2 & 263,4 \\
\hline Цена реализации 1 ц зерна, руб. & 375 & 280,8 & 310,5 & 305,6 & 389 & 334,9 \\
\hline $\begin{array}{l}\text { Затраты в расчете на } 1 \text { га посева зерно- } \\
\text { вых, руб. }\end{array}$ & 5392 & 7983 & 8152 & 10361 & 10632 & 9154 \\
\hline Прибыль на 1 га посева, тыс. руб. & 3 & 0,47 & 1,94 & 0,85 & 3,45 & 1,96 \\
\hline Рентабельность производства зерна, \% & 73,3 & 7,1 & 26,2 & 8,4 & 30,8 & 22,4 \\
\hline Рентабельность продаж зерна, \% & 42,3 & 6,6 & 20,8 & 7,8 & 23,6 & 18,3 \\
\hline $\begin{array}{l}\text { Государственная поддержка производст- } \\
\text { ва зерновых культур в расчете на } 1 \text { га } \\
\text { посевной площади, руб. }\end{array}$ & 7,5 & 3,5 & 5,6 & 3 & 1,4 & 3,5 \\
\hline $\begin{array}{l}\text { Субсидии на продукцию растениеводст- } \\
\text { ва, тыс. руб. }\end{array}$ & 27,3 & 138,7 & 108,4 & 415,6 & 249,6 & 144,6 \\
\hline
\end{tabular}

Анализ экономической эффективности производства зерна в зависимости от его концентрации показал, что в настоящее время рост посевных площадей не дает возможности снизить затраты труда в расчете на единицу площади и 1 ц продукции. Производственные затраты на 1 га посевов в сельскохозяйственных организациях первой группы ниже по сравнению с другими группами. Себестоимость 1 ц зерна составила 197,7 руб., что меньше по сравнению со средней по совокупности на 68,8 руб., цена реализации выше на 40,1 руб. Можно предположить, что доминирующая величина цены продаж зерна в первой группе объясняется его качественными характеристиками. Качество продукции является одним из необходимых условий эффективной работы агропромышленных предприятий в настоящее время, считают многие, экономисты-аграрники [3], и оно характеризуется рядом признаков, часть которых непосредственно связана с количеством. Следовательно, продукция более высокого качества в одном случае позволяв обходиться меньшим количеством для удовлетворения тех же потребностей, в других случаях - более 1 полно в качественном отношении удовлетворяет сами потребности.
Уровень рентабельности производства в первой группе составил 73,3\%, что на 50,9 п.п. вышел по сравнению со средним уровнем по исследуемой совокупности. Но урожайность зерновых культ в первой группе несколько ниже по сравнению с другими и со средней по совокупности.

Авторские расчеты подтверждают исследования ученых [2] о развитии малых форм хозяйствования аграрного сектора экономики в посткризисных условиях.

Фундаментальный вывод их исследования состоит в том, что субъекты малых форм хозяйствования оказались более устойчивыми к воздействию экономически неблагоприятных факторов внешней среды, несмотря на поддержку государством крупных организаций и посредников. Выводы ученых совпадают с мировой тенденцией развития экономики: превосходство малых форм хозяйствования по сравнению с крупными организациями в эффективности и производительности труда.

Для более углубленного изучения влияния различных факторов на эффективность возделывания зерновых культур необходимо проследить зависимость показателей эффективности производства от уровня специализации хозяйств Орловской 
области (табл. 2). Данные группировки показывают, что во второй группе, где доля выручки от продажи зерна в общей сумме выручки колеблется от 30 до 50 \%, показа- тели эффективности выше по сравнению с другими группами и со средними данными по совокупности.

Таблица 2 - Влияние специализации хозяйств Орловской области на эффективность производства зерна, 2010 г.

\begin{tabular}{|c|c|c|c|c|c|c|}
\hline \multirow{2}{*}{ Показатель } & \multicolumn{5}{|c|}{$\begin{array}{c}\text { Доля выручки от продажи зерна в общей сум- } \\
\text { ме выручки, \% }\end{array}$} & \multirow{2}{*}{$\begin{array}{c}\text { В среднем } \\
\text { по совокуп- } \\
\text { ности }\end{array}$} \\
\hline & до 30 & $\begin{array}{c}30 \\
1-50\end{array}$ & $\begin{array}{c}50 \\
1-70\end{array}$ & $\begin{array}{c}70 \\
1-90\end{array}$ & $\begin{array}{l}\text { свыше } \\
90\end{array}$ & \\
\hline Количество сельскохозяйственных организаций & 14 & 6 & 16 & 5 & 7 & 50 \\
\hline Площадь зерновых культур, га & 2466 & 4848 & 2414 & 1441 & 3650 & 2700 \\
\hline Урожайность, ㄴ/ га & 32,5 & 45,6 & 26,5 & 33,1 & 36,2 & 34,3 \\
\hline Производственная себестоимость 1 ц зерна, руб. & 286,6 & 197,8 & 289,1 & 249,9 & 320,2 & 266,5 \\
\hline Себестоимость 1 цреализованного зерна, руб. & 263 & 263,1 & 265,3 & 247,5 & 313,5 & 263,4 \\
\hline Цена реализации 1 ц зерна, руб. & 317,5 & 391,1 & 288,2 & 320,9 & 324,5 & 334,9 \\
\hline Затраты в расчете на 1 га посева зерновых, руб. & 9313 & 9029 & 7655 & 8271 & 1160 & 9154 \\
\hline Прибыль на 1 га посева, тыс. руб. & 0,96 & 5,96 & 0,71 & 2,1 & 0,39 & 1,96 \\
\hline Рентабельность производства зерна, \% & 20,7 & 48,6 & 8,6 & 29,7 & 3,5 & 22,4 \\
\hline Рентабельность продаж зерна, \% & 17,2 & 32,7 & 7,9 & 22,9 & 3,4 & 18,3 \\
\hline $\begin{array}{l}\text { Государственная поддержка производства зерно- } \\
\text { вых культур в расчете на } 1 \text { га посевной площади, } \\
\text { руб. }\end{array}$ & 3,8 & 5,5 & 2,2 & 5,8 & 2,3 & 3,5 \\
\hline $\begin{array}{l}\text { Субсидии на продукцию растениеводства, тыс. } \\
\text { руб. }\end{array}$ & 196 & 52 & 153,7 & 8,4 & 239,3 & 144,6 \\
\hline
\end{tabular}

Различия по уровню специализации в хозяйствах области значительны. Амплитуда колебания по удельному весу выручки от продажи зерна в общем объеме реализации составляет 98,7\%: от 1,3\% (OAO Агрофирма «Ливенское мясо») до $100 \%$ (ООО «Тим» Ливенского района). Значительная часть (28\%) сельскохозяйственных организаций сосредоточена в группе с удельным весом выручки от продажи зерна до $30 \%$ и $32 \%$ хозяйств - с долей 50,1 $70 \%$.

Исследования показали, что максимальная результативность финансовохозяйственной деятельности достигнута в сельскохозяйственных организациях второй группы (доля выручки от продажи зерна составляет $30,1-50 \%$ ). В этой группе урожайность зерновых составила 45,6 ц/га, произ ᄀводственная себестоимость 197,8 руб., что ниже, чем в среднем по совокупности на 68,7 руб., цена реализации зерна 391,1 руб., что выше среднего уровня по рассматриваемым хозяйствам на 56,2 руб. Прибыль в расчёте на 1 га посева зерновых во второй группе хозяйств составила 5,96тыс. руб., что в три раза больше среднего показателя. Рентабельность производ- ства и рентабельность продаж в этой группе организаций также максимальная - 48,6 и $32,7 \%$ соответственно (в среднем по совокупности 22,4 и $18,3 \%$ ). Государственная поддержка производства зерновых культур в расчете на 1 га посевной площади в группе со специализацией $30,1-50 \%$ составила 5,5 руб., субсидии на продукцию растениеводства в целом - 52 тыс. руб.

Нельзя не отметить, что в эту группу хозяйств вошла показательная организация ЗАО «АПК Юность» Должанского района, удельный вес выручки от продажи зерна которой составил 44,9\%, урожайность - 64 ц/га, удельный вес посевов зерновых культур в общей площади посевов составил 57 $\%$, затраты на 1га посевов зерновых 9,84тыс. руб., рентабельность производства зерновых - 63,5 \%.

На каждом этапе развития сельского хозяйства особое внимание уделяется наиболее рациональному и эффективному использованию материальных, трудовых, финансовых ресурсов, а также природных богатств, чтобы обеспечить увеличение производства продукции при наименьших затратах. Себестоимость продукции растениеводства оказывает влияние не только на 
прибыльность этой важнейшей отрасли сельскохозяйственного производства, но и на экономические результаты деятельности животноводческих отраслей, следовательно, и всей сельскохозяйственной организации.

С увеличением производственных затрат в расчете на 1 га посева зерновых культур растут урожайность, себестоимость 1 ц зерна и цена реализации единицы продукции. Так, в первой группе, где в среднем затрачивается до 5 тыс. руб. на 1 га, урожайность составила 24 ц/га, себестоимость - 166,4 руб., цена реализации 256,2 руб. В пятой группе, где производственные затраты превышают 11 тыс. руб. в расчете на 1 га посева зерновых, урожайность - 37,1 ц/га, себестоимость - 340,1 руб., цена реализации - 371,5 руб. Наилучшие результаты хозяйствования достигнуты в четвертой группе (производственные затраты в расчете на 1 га колеблются от 9тыс. руб. до 11 тыс. руб.): урожайность зерновых - 42,4 ц/га, что на 23,6 \% выше по сравнению со средней по рассматриваемой совоᄀкупности хозяйств юго-восточной зоны Орловской области; себестоимость 1 ц - 235,9 руб., что на 30,6 руб. ниже по сравнению со средней себестоимостью, цена реализации выше на 24,9 руб. В этой группе получена максимальная прибыль в расчете на 1 га - 33445 руб., что выше среднего уровня на 1483 руб. Уровень рентабельности составил $27 \%$, что также выше уровня по совокупности.

Высокие показатели эффективности первой группы объясняются низким значением себестоимости 1 ц зерна - 166,4 руб., что ниже среднего уровня по совокупности на 100,1 руб. или на $37,6 \%$, а превышение средней цены реализации над соответствующими показателями первой группы составило 23,5\%. Отсюда высокие значения уровня рентабельности $(42 \%)$ и прибыли в расчете на 1 га посева зерновых (2293 руб.).

Проведенный анализ показывает слабые стороны развития отечественного сельского хозяйства и поднимает проблему совершенствования системы ценообразования на сельскохозяйственную продукцию. Уровень затрат на 1 га выше там, где больший уровень интенсивности и где низкий уровень эффективности использования вложений. Больший объем вложений при менее благоприятных условиях может приводить к более высокой себестоимости.

Огромное значение для развития аграрного сектора имеет механизм эффективности государственной поддержки сельскохозяйственных товаропроизводителей [6]. Данная проблема вызывает в последнее время острую дискуссию. Мировой финансовый кризис оказал свое негативное влияние и на страхование посевов сельскохозяйственных культур. Снижение интереса к страхованию урожая с государственной поддержкой отразилось на многих показателях [7]. В среднем по сельскохозяйственным организациям Орловской области сумма бюджетных средств в расчете на 1 га посева составила всего 3,54 руб. На долю государственной поддержки страхования урожая сельскохозяйственных культур приходится всего 0,34\% стоимости валового сбора зерна (в 2007г. - 2,08\%). Этот показатель намного ниже, чем по стране (5\%), и значительно ниже, чем в зарубежных странах (Евросоюз - 35\%, США - 17\%) [8]. Уменьшение объема выделяемых средств в расчете на 100га посевов зерновых культур в 4,6 раза за рассматриваемый период объясняется в первую очередь значительным снижением самой поддержки, а во вторую очередь - ростом посевной площади на $22,5 \%$.

В настоящее время в России наиболее масштабно используется механизм субсидирования взносов в страховании урожая сельскохозяйственных культур. В 2011 г. именно на этот вид страхования предусмотрена субсидия из федерального бюджета в сумме 5 млрд. руб, что это позволит значительно расширить охват страхованием сельскохозяйственных производителей, повысит эффективность их страховой защиты от природных явлений, обеспечит финансовую устойчивость и стабильность сельскохозяйственного производства. 


\section{БИБЛИОГРАФИЯ}

Гуляева Т.И., Сидоренко О.В. Рост производства сельскохозяйственной продукции - основа продовольственной безопасности регионов // Экономический анализ: теория и практика. 2010. № 12.

Гусев В.В., Пышкин А.Н. Малые формы хозяйствования в АПК в условиях кризиса // Экономика сельского хозяйства России. 2011. № 2.

Жученко А.А. Возможности старта Российского АПК в XXI столетии // Экономика сельскохозяйственных и перерабатывающих предприятий. 2010. № 11.

Иващенко Т.Н., Цвырко А.А. Направления государственной поддержки аграрного производства региона // Вестник Орловского государственного аграрного университета.

Орел: Изд-во Орёл ГАУ, № 4(31), 2011.

Ильина И.В., Сидоренко О.В. Состояние и тенденции развития зернового хозяйства региона // Национальные интересы: приоритеты и безопасность. 2011. № 7.
Коротнев В., Чалов С. Эффективность сельскохозяйственного страхования с государственной поддержкой // Агрострахование и кредитование. 2010. № 8.

Цвырко А.А. Финансовое обеспечение аграрного сектора экономики // Известия Тульского государственного университета. Экономические и юридические науки. Вып. 1., ч. 2 Тула: Изд-во ТулГУ, 2011.

Цвырко А.А. Государственное регулирование и поддержка сельского хозяйства за рубежом // Известия Тульского государственного университета. Экономические и юридические науки. Вып. 2., ч. 2 - Тула: Изд-во ТулГУ, 2011. 